raised all the upright stones, the transport of the recumbent stone (typically of 20 tonnes or more) required the combined efforts of the able-bodied members (and perhaps the males only) of a number of families. This provides a tantalizing glimpse of community action, and perhaps of a clan organization, in the late third and early second millennium $\mathrm{BC}$; but its details are beyond the limits of valid inference from the evidence.

Burl also shows, in more detail than in his earlier book, that the position of almost all the recumbent stones lies within the azimuth range of the moon at its minimum declination; and he therefore posits a symbolic link between the moon and the dead who sanctified these sites.

In the remaining hundreds of stone circles elsewhere there is little to be seen of any recurrent pattern, save that they are of stone and approximately circular. Some but not all of the few which have been comprehensively excavated have produced burials, but again of a token or dedicatory kind, or as manifestly later additions, in the Early Bronze Age, to monuments built centuries before. They vary greatly in size, from the huge ring at Avebury to tiny circles which would very nearly fit into the study in which I write this review; and in date they seem to cover a period of about two thousand years, starting around 3,500 BC. Within such wide ranges it is probably futile, as Burl implicitly recognizes, to seek any simple or universal explanation. It is better to admit, however reluctantly, that there are many interesting questions about the prehistoric past which are per se unanswerable, simply because there are no documents to give a clue to motives. Motive, except in the trivial sense of intending to do what was done, cannot be inferred from inanimate objects and structures. In answer to the question 'Why?' the evidence is dumb.

This otherwise excellent book dismisses too forthrightly the putative evidence from stone circles for the early development of scientific concepts. For Burl, the megalithic yard is "a chimaera, a grotesque statistical misconception". It is indeed a product of statistical inference; but two independent treatments of the data by different means have agreed, at the least, that further investigation is necessary
(Trans. R. Soc. Lond. A276, 1974; J. R. stat. Soc. A139, 1976).

Burl likewise implicitly rejects Thom's hypotheses about how the non-circular rings (flattened circles, eggs, compound rings) were set out, on the grounds that alternative constructions, using only pegs and a loop of measuring cord, yield an equally good fit to the stones surveyed. He may be right; but he ignores or evades the point that even if these shapes, manifestly deliberate and not accidental, are no more than the fossilized remains of games with pegs and string, they none the less constitute the foundations, gropingly laid maybe, of pure mathematics.

The astronomical aspects of stone circles can be assessed only statistically, using the largest samples available, because putatively significant alignments can obviously occur by chance. Independent checks of the claims of Thom and his followers are only now in progress. Their outcome should not be prematurely judged, in advance of publication.

R. J. C. Atkinson is Professor of Archaeology at University College, Cardiff, UK.

\section{Electronic theory of cancer}

\section{M. Coombs}

Submolecular Biology and Cancer. Ciba Foundation Symposium, No. 67. Pp. 349. (Excerpta Medica: Amsterdam, 1979.) $\$ 42.50$, Dfl.87.

THIS book reports the proceedings of the 67th Ciba Foundation symposium, held in honour of Albert Szent-Györgyi on the occasion of his 85th birthday in 1978 .

In an introduction by the Chairman ( $R$. J. P. Williams) it is noted that although "submolecular" refers to systems at a lower level than whole molecules, in the present context it is largely confined to electrons. Szent-Györgyi next outlines his views on "the living state and cancer", and the possible relationships between submolecular biology and cancer are enumerated. The greater part of the book is devoted to fifteen lectures, each with its own discussion, and ends with a general consideration of Szent-Györgyi's hypothesis.

The sharp distinction between living and inanimate matter leads Szent-Gyorgyi to conclude that a specific physical state underlies life. The subtle reactivity of living systems is thought of as an inherent property of the constituent proteins, brought about by removal of single electrons from their otherwise fully occupied orbitals. Positive electron holes thus produced lead to electrieal conductivity, with the ability of the desaturated proteins to carry information in the form of electrical signals. It is proposed that "the living state is the electronically desaturated state of molecules, and the degree of development and differentiation is a function of the degree of electronic desaturation'. When life began on Earth the atmosphere lacked molecular oxygen; electronic desaturation of proteins was accomplished by simple aldehydes, such as methylglyoxal $\left(\mathrm{CH}_{3}\right.$. CO.CHO), which are good electron acceptors. This led to a low degree of development, termed the $\alpha$-state. Later the advent of atmospheric oxygen, a much better electron acceptor, led to the highly developed $\beta$-state existing today. Here a related molecule, ascorbic acid (vitamin C), acts essentially as a catalyst for the electronic desaturation of proteins by oxygen. Cancer is thought of as a reversion to the $\alpha$-state.

It is obvious from the studies described in the subsequent chapters that little evidence can be found for electrical conductivity in proteins treated with electron acceptors, although here the virtual impossibility of making measurements on proteins in their native state may obscure true results. Nor is the anti-cancer activity of certain aldehydes apparently mediated in the way suggested by the hypothesis; moreover, it now seems very doubtful whether vitamin $C$ is useful in the clinical treatment of the disease. Furthermore, experiment does not support the idea that there are differences in free radical levels between normal and tumour

\section{IMAGE UNAVAILABLE FOR
COPYRIGHT
REASONS}

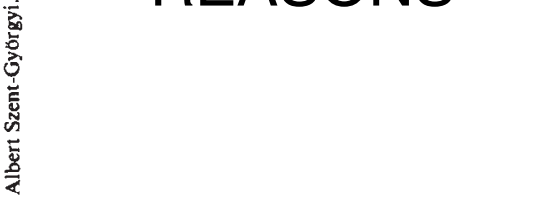

cells. However, R. Damadian, in developing the technique of whole-body nuclear magnetic resonance scanning, can distinguish normal from cancer tissue by the prolonged relaxation of protons in the latter. This indicates increased disorder in the structure of water in tumours, but just how this ties in with Szent-Gyorgyi's theory is unclear. To summarize, it is disappointing that this novel hypothesis has so far failed to find solid experimental confirmation.

The book is well produced and free from errors; its cost does not seem unreasonable in this age of unreasonable prices.

M. M. Coombs is in the Chemistry Laboratory, Imperial Cancer Research Fund, Lincoln's Inn Fields, London, UK. 